\title{
INVESTIGATING THE RELATIONSHIP BETWEEN ORGANIZATIONAL LEARNING AND FLEXIBILITY OF EMPLOYEES IN EDUCATION DEPARTMENT OF SARPOOL-E-ZAHAB CITY
}

\author{
Iran Ghanbari \\ Department of Management, Sanandaj Branch, Islamic Azad University, Sanandaj, Iran \\ Nariman Abdi \\ Department of Management, Sanandaj Branch, Islamic Azad University, Sanandaj, Iran \\ n2093abdi@yahoo.com
}

\begin{abstract}
The flexibility of human resources is one of the most important aspects of organizational flexibility and is focused on adaptability of employee's characteristics (such as knowledge, skills and behavior) with changing environmental conditions. This study aimed to investigating the relationship between organizational learning and flexibility of employees in education department of Sarpool-e-zahabcity. The study population included all employees of education in Sarpool-e-zahabcity which were 1,300 people. Among these samples using simple random sampling method, a sample of 297 subjects was selected according to Cochran formula. This study in terms of aim is applied research and in terms of data collection is descriptive and correlational. In this study, a questionnaire to collect data and to confirm the questionnaire validity from expert's perspective and SPSS software was used to assess the reliability and Cronbach's alpha for organizational learning questionnaire and organizational learning both were above 0.7, indicating high reliability of the questionnaire. In this study, for data analysis, SPSS software and Pearson correlation and multiple regression were used, the results suggest that there is a significant positive relationship between organizational learning aspects (shared vision, organizational culture, team work and learning, knowledge sharing, system thinking, participative leadership and competence development) and employee's flexibility, regression results indicate that the shared vision more than other variables affect the flexibility of employees.
\end{abstract}

Keywords: Organizational learning, Employee's flexibility, Education department in Sarpool-ezahabcity

\section{INTRODUCTION}

Undoubtedly, in the current turbulent world that has growing environmental changes; organizations will not only survive in the future, but also want to maintain their power. To this end, organizations should constantly keep pace with changes in the environment and keep pace with changes in organizational learning groups. Organizational learning issue recently has attracted much attention in the field of organizational behavior and strategic management [1]. Organizational learning is one of the important issues that have been raised in recent decades. Organizational learning, knowledge and understanding of the process of improving actions is through better organization [2]. Organizational learning refers to the capacity of the organization to change and continuous improvement [3]. On the other hand, human resources are a key factor for increasing competitiveness, innovation and competitive advantage by organizations. The source, having the characteristics such as value creating, rare and difficult to imitate, providing context to improve the ability of organizations.

Organizations achieve lofty goals need to optimal skills and behaviors of human resource and efficient functions of human resources management that fulfill these conditions require flexibility of human 
resources [4]. Flexibility as an indicator of the link between the system and its external environment to absorb the uncertainty, dynamics of the system as well as the ability to change and adapt can be considered.

\subsection{Operational definition of organizational learning}

In this research, organizational learning based on research Neif (2001) in seven dimensions, shared vision, organizational culture, team work and learning, knowledge sharing, systems thinking, team leadership and competence development will be studied [5].

\subsection{Operational definition of flexibility of human resources}

In this study, flexibility of human resources as an internal feature or features based on research (Right and Snell, 1999) in three dimensions, functional flexibility, skills flexibility and behavioral flexibility will be investigated [6]. From the perspective of critical capabilities, flexibility enables the company by diverse and changing requirements and adapts to external environment and reaches competitive advantage and higher performance and maintains it. Human resources flexibility is a wide range of organizational design and management theory models such as: Social-technical systems theory, self-organization, little production and timely production management. Human resource flexibility as a means to improve production performance has been recognized because provides several strategic advantages. The use of multitasking human resources allows the company quickly to respond the unforeseen and unbalanced demands that may arise in the sectors.

Such flexibility helps companies to reduce the turnaround time for production and work inventory in process and improve customer service, while providing more efficient use of human resources and equipment. Flexibility patterns were considered first by Atkinson. Atkinson model based on key employees-centered and secondary on three types of functional flexibility, numerical flexibility and financial flexibility has been introduced, the strategic vision about flexibility has become a controversial issue in organizational theory. Of course, use of flexible patterns is more complex than the view that in the Atkinson model is designed. Future research in this area was conducted in two model temporary flexibility and local flexibility was also determined [16]. A summary of the types of flexibility patterns in Table 1 is expressed.

Table 1: Summary of all flexibility patterns [16]

\begin{tabular}{|l|l|l|}
\hline $\begin{array}{l}\text { Pattern } \\
\text { Name }\end{array}$ & Definition & Example \\
\hline Functional & $\begin{array}{l}\text { The company rents up against the boundaries of the } \\
\text { traditional structure use their employees in different } \\
\text { places. }\end{array}$ & $\begin{array}{l}\text { Multi-skilled employees, jobs } \\
\text { that require few different skills }\end{array}$ \\
\hline Numerical & $\begin{array}{l}\text { Allows companies according to a company needs uses } \\
\text { different employees at different times }\end{array}$ & $\begin{array}{l}\text { temporary employees, seasonal, } \\
\text { casual and fixed-term } \\
\text { employees hired through } \\
\text { employment agencies and } \\
\text { outsourcing part-time, }\end{array}$ \\
\hline Temporary & $\begin{array}{l}\text { Allowing the company to apply regular and irregular } \\
\text { variability in working hours. }\end{array}$ & $\begin{array}{l}\text { Annuity contracts or partime-varying, have } \\
\text { overtime, time } \\
\text { reduced working time }\end{array}$ \\
\hline Local & $\begin{array}{l}\text { Employee's using outside the workplace that includes } \\
\text { entrust work to do outside the workplace }\end{array}$ & $\begin{array}{l}\text { Home, Mobile, Telephone and } \\
\text {. }\end{array}$ \\
\hline Financial & $\begin{array}{l}\text { To allow companies to take on the performance of the } \\
\text { company increase or reduce employee's paid bills. }\end{array}$ & $\begin{array}{l}\text { Profit-sharing, sharing of } \\
\text { results, different programs } \\
\text { payments }\end{array}$ \\
\hline
\end{tabular}

Submit Date: 10.05.2016, Acceptance Date: 25.06.2016, DOI NO: 10.7456/1060JSE/040 


\subsection{Objectives and hypotheses}

The main objective of this study was to identify the relationship between organizational learning and flexibility of employees in education department of Sarpool-e-zahabcity while secondary objectives are:

- Identify relationships between the components of organizational culture and flexibility of employees in education department of Sarpool-e-zahabcity.

- Identify relationships between the components of team work and learning and flexibility of employees in education department of Sarpool-e-zahabcity.

The main hypothesis of this study is that there is a significant relationship between organizational learning and flexibility among employees in education department of Sarpool-e-zahabcity. The hypothesis of this study is defined as follow.

There is a significant relationship between the components of organizational culture and flexibility of employees in education department of Sarpool-e-zahabcity.

There is a significant relationship between the components of team work and learning and flexibility of employees in education department of Sarpool-e-zahabcity.

Considering that this research aimed to investigate the relationship between organizational learning and flexibility of employees in education department of Sarpool-e-zahabcity so this research among is applied research.

In term of data collection method the study is non-experimental (descriptive).

Because the study also examines the relationship between variables using data collection among employees will take action and in a line with descriptive studies of correlational branch, and in particular is a type of structural equation modeling.

In the second part a review of prior research will be discussed. The research method in the third and fourth quarter results is discussed. Summarize findings also expressed in the fifth and final section.

\section{REVIEW OF THE LITERATURE}

Chen et al in a study to investigate the relationship between human resource management flexibility and innovation performance of companies in terms of their organizational learning capabilities. Results show that: 1) functional flexibility and behavioral flexibility has significant positive effects on organizational learning capability; 2) skills flexibility lead to improve organizational learning. So the company cans functional flexible strategy, skills flexible strategy and behavior flexible strategy to improve innovation performance in company. On the other hand, organizational learning capabilities act as a mediator between flexible human resource management and performance of organizational innovation [8].

Imran and Rizoy in a study investigated the relationship between organizational learning and organizational performance in Pakistan banks. The results showed that organizational learning increase employee's motivation and play a significant role in performance. Another finding of this study suggested there was a significant relationship between organizational learning and increase innovative activities in enterprises and job assignments [9].

Yakl in a research on organizational learning found that organizational learning is a crucial factor in longterm function and survival of the organization and there is a significant relationship between organizational learning and self-employment levels and flexibility of employees, which contributes to the development of organizational entrepreneurship [10].

Nife in his thesis compares the level of maturity of organizational learning from colleges and universities participating in traditional and non-traditional medicine. The aim of this study was to compare the maturity level of organizational learning from colleges and universities participating in the traditional and non-traditional accreditation processes. Research tool for quantifying management practices in colleges

Submit Date: 10.05.2016, Acceptance Date: 25.06.2016, DOI NO: 10.7456/1060JSE/040 
and universities than the integral components of a learning organization was developed. Subjective opinions polls from twelve colleges and universities obtained. The results show that the dimensions of organizational learning in non-traditional medicine techniques in universities are more effective than traditional medicine [6]

Behatnager in a study investigates the strategic role of human resources, organizational ability to learn and psychological empowerment on organizational commitment. The results show that there is a relationship between strategic human resource management and organizational commitment as well as the ability to learn and psychological empowerment using strategic mediating role of human resources have a significant indirect relationship on organizational commitment. [11]

Shepard an article titled "Consolidation of organizational learning and information and communication technology in teaching and learning case study on 15 schools in one province of Canada has done.

The results of this study showed that the use of ICT in teaching and learning largely depends on the level of organizational learning in special schools [12]. Nife in a research at the University of Wisconsin entitled "Comparison of the organizational learning factors in universities that performed academic quality improvement project (AQIP) (modern university) and universities that have not implemented the project (traditional universities), the results of this research has indicated that there if difference between organizational learning factors in traditional universities and modern universities.

Although most universities (traditional and modern) have enjoyed a major feature of organizational learning, but overall indicator of organizational learning showed that organizational learning in modern university has a higher level than traditional university [13]. Charles Harvey and John Dan Tone in a study aimed to find ground in promote organizational learning in few large firms. The results showed that the necessity of changing trade environment is a wide agreement in this regards that element of knowledge are an important factor in spreading organizational learning. Also the competitive culture encouraged new ideas, risk taking and employee participation in decision-making factors underlying learning [14].

Demosky and Sherlavej in a research entitled organizational learning and ICT: conducted a link promising over 220 top managers of 867 business companies in Slovakia. The results of this study showed that there is a positive relationship between organizational learning and information and communication technology [15].

\section{RESEARCH METHODOLOGY}

\section{Population, sampling method and sample size}

The study population included all employees of education department in Sarpool-e-zahabcity that they refer to the organization were 1300 employees. In this study, a simple random sampling method available is used.

\section{Methods and tools to analyze the data}

In this study to evaluate the reliability of questionnaire Cronbach test and to test normality of data Kolmogorov-Smirnov test was used and data obtained from the questionnaire distributed in two parts of descriptive and inferential statistics will be analyzed.

Thus, to analyze the data descriptive-statistical methods and to examine the relationship between independent and dependent variables correlation tests and for regression SPSS software was used.

Cochran formula used for determining sample size in this study, which calculated as follows:

$$
\mathrm{n}=\frac{N Z_{\frac{a}{2}}{ }^{2} p(1-p)}{\varepsilon^{2}(N-1)+Z_{\frac{a}{2}}{ }^{2} p(1-p)}=\frac{1300 * 1 / 96^{2} * 0 / 5 * 0 / 5}{0 / 05^{2}(1300-1)+1 / 96^{2} * 0 / 5(1-0 / 5)}=297
$$


$\mathrm{N}=1300$ population size

$\mathrm{P}=0.5$ probability of adjectives

$\mathrm{Z} \frac{\alpha}{2}=1.96$ Determination coefficient of critical factor

$\epsilon=0.05$ Error value

$\mathrm{n}=$ number of samples

Simple random sampling method used in this study. In this study to collect data both library and field methods used.

\section{Methods and scoring variables}

Organizational flexibility questionnaire is regulated by 3 dimensions, which contains 9 question based on the Likert scale. Questions 1 to 3 determine score of functional flexibility, Question 4 to 6 measure skill flexibility Questions 7 to 9 measures behavioral flexibility. In Table 2 scoring methods have been brought to the statements of the questionnaire [17].

Table 2: The structure of organizational flexibility questionnaire

\begin{tabular}{|l|l|l|l|l|l|l|}
\hline Dimensions & Questions & too much & Much & Average & Little & $\begin{array}{l}\text { very } \\
\text { little }\end{array}$ \\
\hline Functional & $\mathbf{3}$ ت1 & $\mathbf{5}$ & $\mathbf{4}$ & $\mathbf{3}$ & $\mathbf{2}$ & $\mathbf{1}$ \\
\hline Skill & $\mathbf{4}$ to $\mathbf{6}$ & $\mathbf{5}$ & $\mathbf{4}$ & $\mathbf{3}$ & $\mathbf{2}$ & $\mathbf{1}$ \\
\hline Behavioral & $\mathbf{7}$ to 9 & $\mathbf{5}$ & $\mathbf{4}$ & $\mathbf{3}$ & $\mathbf{2}$ & $\mathbf{1}$ \\
\hline
\end{tabular}

\section{Reliability}

The reliability is one of the technical features of the instrument show that instrument to what extent provides similar results in the same conditions. Reliability coefficient ranges is from zero (no correlation) to positive one (perfect relationship). Reliability coefficients indicate the extent to which the instrument is stable [18]. There are different methods for calculating reliability. The most famous of them is Cronbach's alpha and for calculating internal consistency of the instrument used to measure various properties.

$$
\alpha=\frac{k}{k-1}\left(1-\frac{\sum_{i=1}^{k} S_{i}^{2}}{\sigma^{2}}\right)
$$

The relationship between k number of questions, variance I ${ }^{\text {th }}$ question, $S_{i}^{2}$ variance of total questions.

Cronbach's alpha correlation coefficient, is a value between 0 and 1 steady if a questionnaire is reliable that Cronbach's alpha values is greater than 0.7. And closer to 1 of the questionnaire has higher reliability. In the present study to measure the reliability of the questionnaire, Cronbach's alpha for the 30 samples of questionnaire is used as pretest. Results of flexibility in table 3 shown.

Table 3: Results of Cronbach's alpha test for questionnaire flexibility

\begin{tabular}{|l|l|l|l|}
\hline Dimensions & $\begin{array}{l}\text { Number of } \\
\text { questions }\end{array}$ & Cronbach's alpha & Total factor \\
\hline Functional & $\mathbf{3}$ & 0.826 & \multirow{2}{*}{$\mathbf{0 . 7 6 0}$} \\
\hline Skill & $\mathbf{3}$ & $\mathbf{0 . 7 7 8}$ & \\
\hline Behavioral & $\mathbf{3}$ & $\mathbf{0 . 7 3 0}$ & \\
\hline
\end{tabular}

According to Cronbach's alpha values of the questionnaire, Cronbach's alpha value of the questionnaire flexibility is more than 0.7 as a result; the flexibility of the questionnaire had high validity.

\section{Data Analysis}

Submit Date: 10.05.2016, Acceptance Date: 25.06.2016, DOI NO: 10.7456/1060JSE/040 
In this section we describe the sample characteristics; collected data can be classified with descriptive statistics indexes, then the descriptive statistics related to variables using parametric or non-parametric inferential statistics confirm or reject hypotheses.

\section{Description of population}

Information about the marital status of respondents is presented in Figure 1. As seen in the table and graph, based on the information contained in tables and graphs (1-4), 174 samples, or $58 \%$ of the respondents were female and 126 samples or $42 \%$ were male. Information on the age of the respondents is presented in Figure 2. As seen in the table and graph, in accordance with the above information 0.4 respondents, 12 people were between 20 and 30 years of age. The most frequent age group 30 to 40 years, which is equivalent to $0.48,144$ samples have formed. 0.40 respondents related to the age group 40 to 50 years and 0.8 in the age group above 50 years.

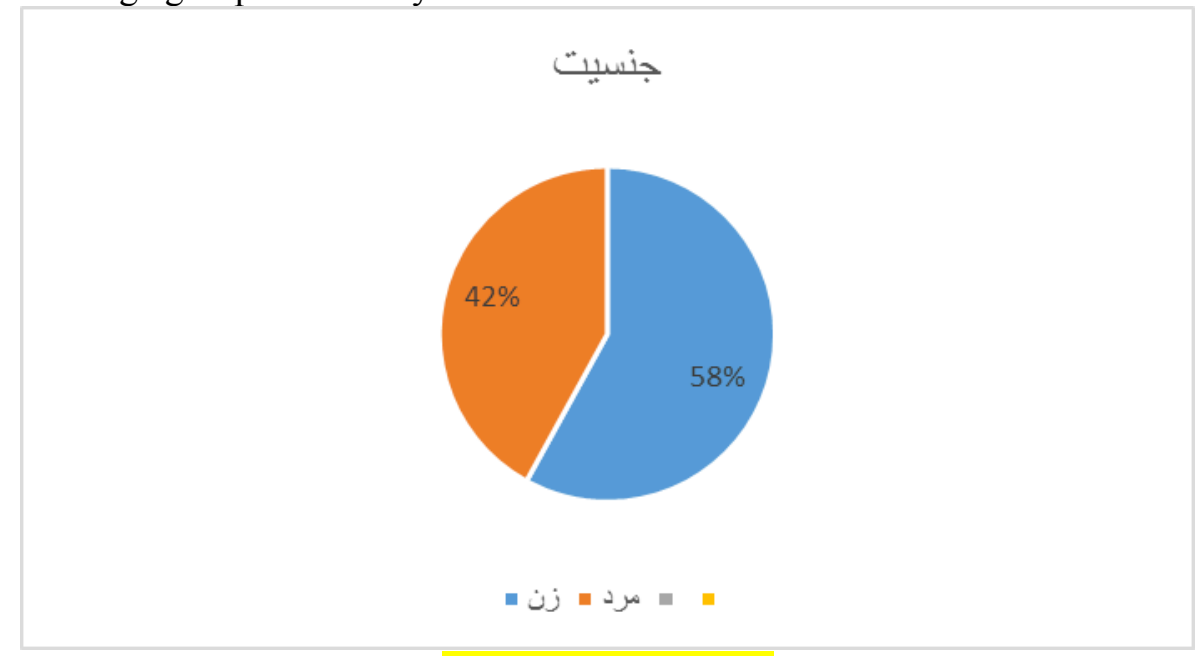

\section{Gender Male Female}

Graph 1: Gender Status of respondents

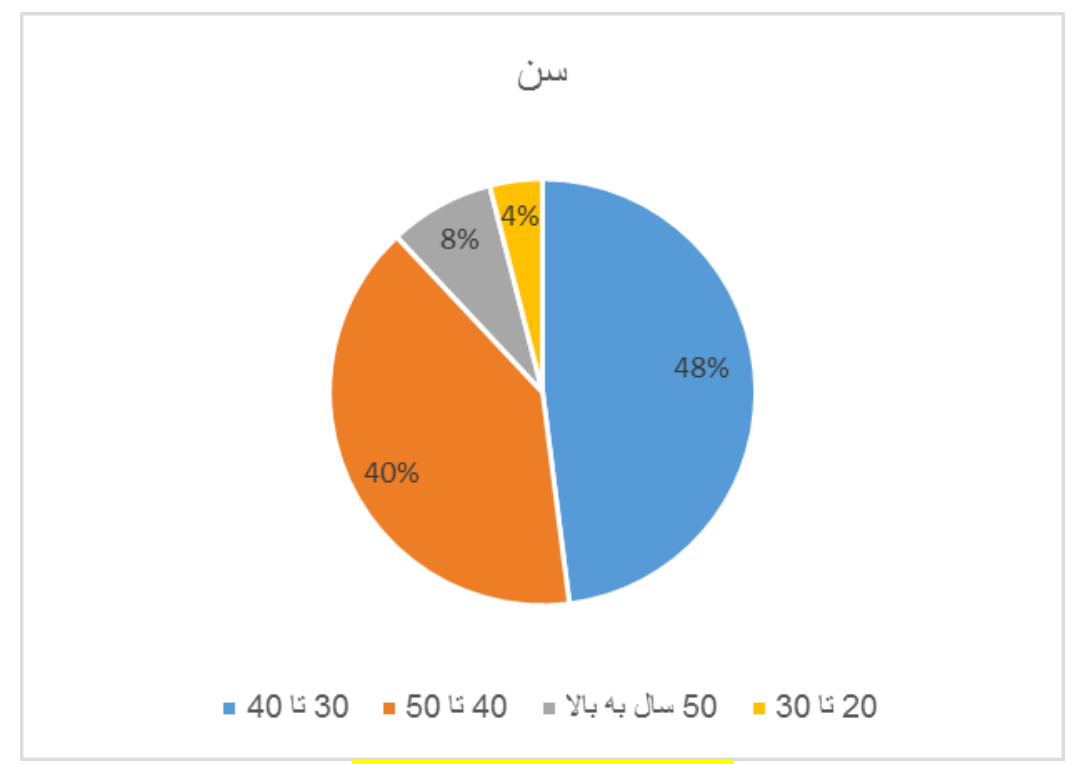

Age Above 50 years old

Graph 2: Age of respondents 
Information on respondent's education is provided in graph 3. As per the tables and graphs can be seen, according to the descriptive results set forth in graphs 3,10 people equivalent to $3.3 \%$ of the total respondents who were high school graduates, 50 people or $16.7 \%$ associate's degree, 216 people equivalent to $72 \%$ bachelor and 24 people or $8 \%$ master and higher. Information on teaching is presented in Figure 4. As per the tables and graphs can be seen, according to the descriptive results set forth in Figure 4, 120 people of total respondents equivalent to $40 \%$, secretary, 132 people equivalent $44 \%$ teachers, 12 people equivalent to $4 \%$ director, 12 people equivalent to $4 \%$, Deputy of education and 24 people equivalent to $8 \%$ deputy education.
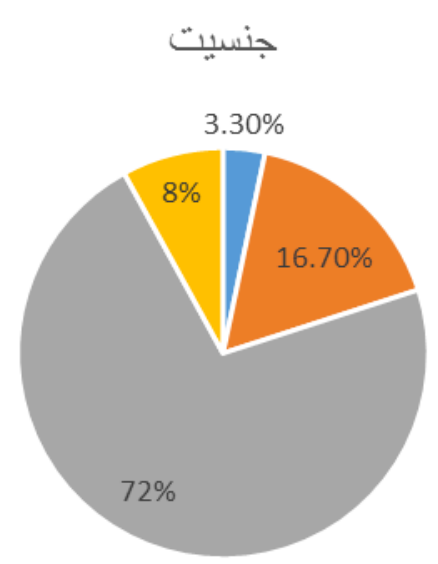

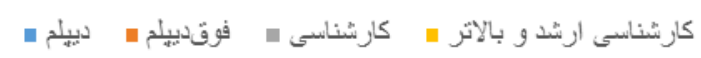

Gender: Associate's degree, Bachelor, Master and higher

Graph 3 Education related to respondents

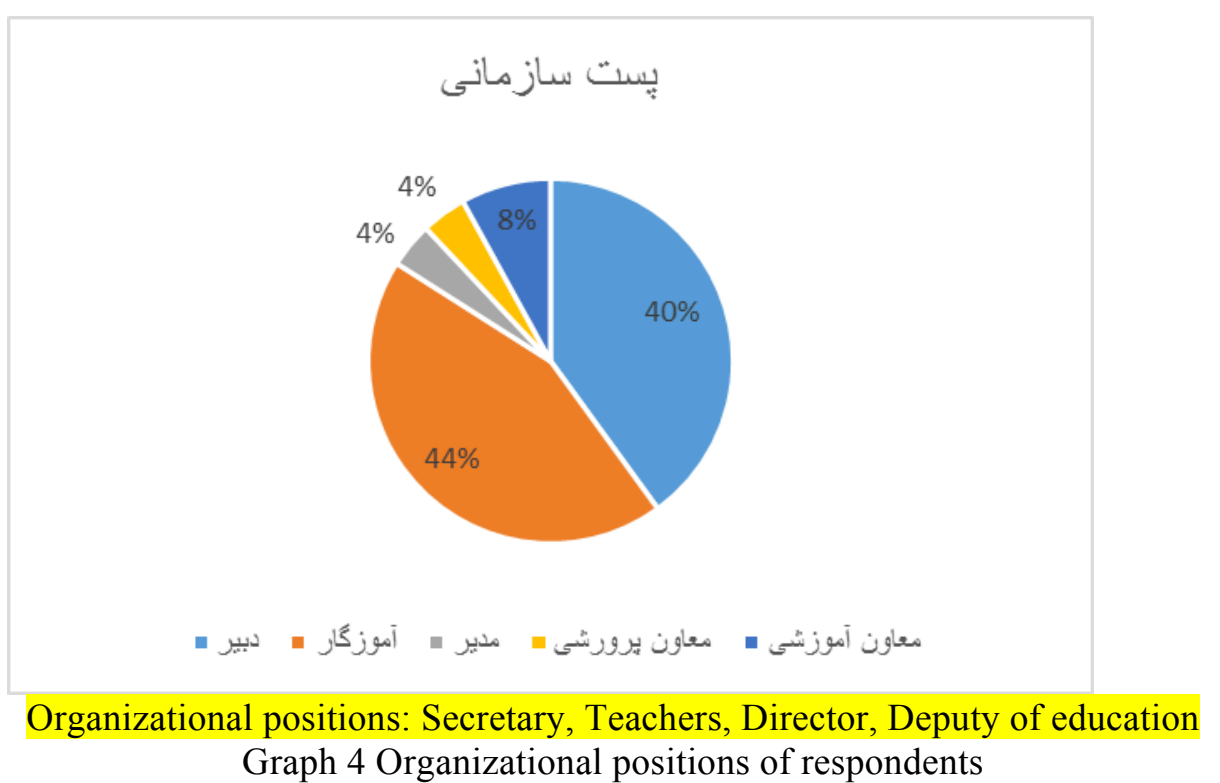

\subsection{Research hypotheses test}

To hypothesis test at first correlation test conducted than the research hypotheses are judged. The correlation coefficients identify variables direction with each other, so that the positive correlation between the two variables move in the same direction and negative correlation means indicates the inverse direction of change of two variables, so that an increase in one leads to a decrease in another. In 
general, the Pearson correlation coefficient, it is examined whether there is a significant relationship between the two variables statistically. In this test the null hypothesis states that there is no significant relationship between the two variables statistically. According to the hypothesis test, assuming type 1 error 5\% null hypothesis cannot be rejected at the time that the probability is greater than $5 \%$. In other words, if the amount sig is less than $5 \%$ then we are in a critical area that represents the null hypothesis rejected or the significance of the relationship between two variables is investigated.

Hypothesis testing correlation between two variables showed statistically as below:

$\mathrm{H}_{0}: \rho=0$

$\mathrm{H}_{1}: \rho \neq 0$

Where, $\rho$ represent the correlation between the two variables. According to what was mentioned in the above in next section pay to examine the research hypotheses.

\section{4-2-1- Correlation test for main hypothesis}

Hypothesis $\mathrm{H} 0$ : there is no significant relationship between organizational learning and flexibility of employees in education department of Sarpool-e-zahabcity.

Hypothesis H1: there is significant relationship between organizational learning and flexibility of employees in education department of Sarpool-e-zahabcity.

In connection with the main hypothesis of the study, data analysis in Table (4-16) is shown. According to the table, the correlation between organizational learning and flexibility of employees in education department of Sarpool-e-zahabcity $\mathrm{P}<0.05$ equal to $(\mathrm{r}=0.942)$, the coefficient is statistically significant. So by taking ( $\operatorname{sig}=0.000)$ in Pearson test, assuming $\mathrm{H} 0$ rejected and $\mathrm{H} 1$ approved that assume there is a significant relationship between organizational learning and flexibility of employees in education department of Sarpool-e-zahabcity.

Table (4-16): correlation coefficient of organizational learning and flexibility

\begin{tabular}{|l|l|l|l|}
\hline \multicolumn{2}{|c|}{} & $\begin{array}{l}\text { organizati } \\
\text { onal } \\
\text { learning }\end{array}$ & Flexibility \\
\hline $\begin{array}{l}\text { organiza } \\
\text { tional } \\
\text { learning }\end{array}$ & $\begin{array}{l}\text { Pearson } \\
\text { correlation } \\
\text { coefficient }\end{array}$ & 1 & $0.942^{* *}$ \\
\cline { 2 - 4 } & Sig & & 0.000 \\
\cline { 2 - 4 } & Number & 300 & 300 \\
\hline
\end{tabular}

\subsubsection{Components of team work and learning and flexibility of education employees in Sarpool-e- zahabcity}

Hypothesis H0: There is not a significant relationship between the components of team work and learning and flexibility of education employees in Sarpool-e-zahabcity.

Hypothesis H1: There is a significant relationship between the components of team work and learning and flexibility of education employees in Sarpool-e-zahabcity.

In connection with third sub-hypothesis of the study, Pearson correlation coefficient in Table (4-11) is shown. According to the table, the correlation between components of team work and learning and flexibility of education employees in Sarpool-e-zahabcity $\mathrm{P}<0.05$ equal to $(\mathrm{r}=0.839)$, the coefficient is statistically significant. So by taking $(\mathrm{sig}=0.000)$ in Pearson test, assuming $\mathrm{H} 0$ rejected and $\mathrm{H} 1$ approved that assume there is a significant relationship between components of team work and learning and flexibility of education employees in Sarpool-e-zahabcity

Table 4: Correlation coefficient between components of team work and learning and flexibility

Submit Date: 10.05.2016, Acceptance Date: 25.06.2016, DOI NO: 10.7456/1060JSE/040 


\begin{tabular}{|c|c|c|c|}
\hline & & $\begin{array}{l}\text { Team work } \\
\text { and learning }\end{array}$ & Flexibility \\
\hline \multirow{3}{*}{$\begin{array}{l}\text { Team } \\
\text { work and } \\
\text { learning }\end{array}$} & $\begin{array}{l}\text { Pearson } \\
\text { correlation } \\
\text { coefficient }\end{array}$ & 1 & 0.839 \\
\hline & Sig & & 0.000 \\
\hline & Number & 300 & 300 \\
\hline
\end{tabular}

\subsubsection{Components of organizational culture and flexibility of education employees in Sarpool-e- zahabcity}

Hypothesis H0: There is not a significant relationship between the components of organizational culture and flexibility of education employees in Sarpool-e-zahabcity.

Hypothesis H1: There is a significant relationship between the components of organizational culture and flexibility of education employees in Sarpool-e-zahabcity.

In connection with third sub-hypothesis of the study, Pearson correlation coefficient in Table (4-10) is shown. According to the table, the correlation between components of organizational culture and flexibility of education employees in Sarpool-e-zahabcity $\mathrm{P}<0.05$ equal to $(\mathrm{r}=0.829)$, the coefficient is statistically significant. So by taking $(\mathrm{sig}=0.000)$ in Pearson test, assuming $\mathrm{H} 0$ rejected and $\mathrm{H} 1$ approved that assume there is a significant relationship between components of organizational culture and flexibility of education employees in Sarpool-e-zahabcity

Table 4: Correlation coefficient between components of organizational culture and flexibility

\begin{tabular}{|l|l|l|l|}
\hline \multicolumn{2}{|c|}{} & $\begin{array}{l}\text { Organizatio } \\
\text { nal culture }\end{array}$ & Flexibility \\
\hline $\begin{array}{l}\text { Organiza } \\
\text { tional } \\
\text { culture }\end{array}$ & $\begin{array}{l}\text { Pearson } \\
\text { correlation } \\
\text { coefficient }\end{array}$ & 1 & $0.826^{* *}$ \\
\cline { 2 - 4 } & Sig & & \\
\cline { 2 - 4 } & Number & 300 & 300 \\
\hline
\end{tabular}

\subsection{Multiple regression test results}

The results of the research hypothesis showed that there is a positive relationship between organizational learning variable and flexibility. But the effect of these factors and which of these factors have greater impact determined by multiple regression tests. In other words, multiple linear regression parametric tests in measuring the explaining amount are dimensions of variables.

\section{1 tests the normality of non-standard residues:}

In the first step normality of non-standard residues of statistical data (variables of organizational learning and flexibility), which is one of the assumptions of multiple regression, is examined. For this purpose, a new column in spss software including non-standard residue calculated, then K-S test performed on columns were created. Based on the test results in Table 6 and histograms 5 , sig $=0.067$, so the assumption $\mathrm{H} 0$ based on the residuals is not normal rejected and $\mathrm{H} 1$ include the assumption of normality of the residuals is accepted.

Table 6: Results of the Kolmogorov-Smirnov test regarding normality of standard Residuals, variables of organizational learning and flexibility

\begin{tabular}{|l|l|l|l|l|}
\hline Variables & Number & K-S value & sig & Normal Results \\
\hline Residuals & $\mathbf{3 0 0}$ & $\mathbf{0 . 9 4 5}$ & $\mathbf{0 / 0 6 7}$ & Normal \\
\hline
\end{tabular}




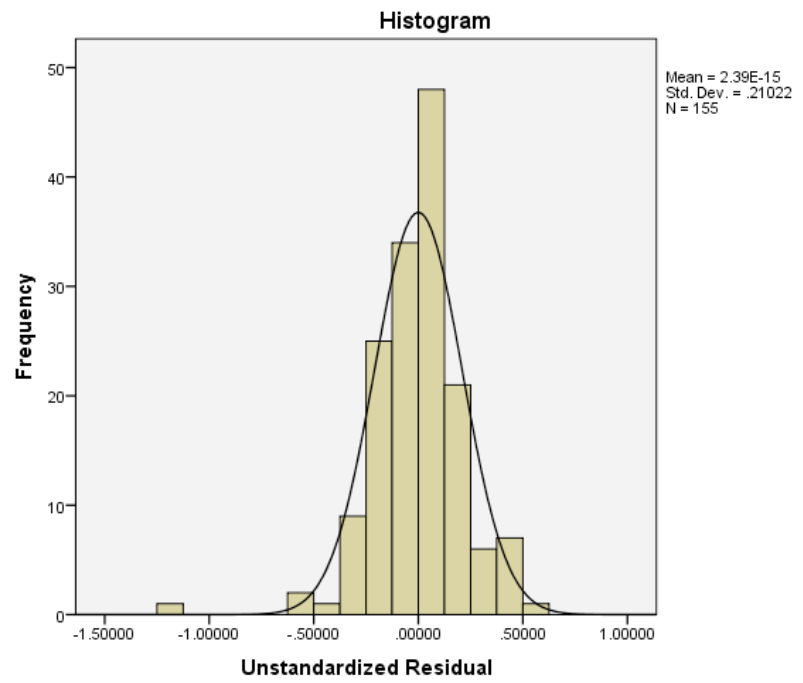

Graph histograms of non-standard residues

\section{Examine the homogeneity of variance, standard residuals:}

The next step graph of predicted values (flexibility) versus the independent variable data (organizational learning) is plotted. If the scatter plots placed in a fixed-band and residual variance is homogeneous.

Otherwise, for example, the pot figure shows the non-homogeneity of residual. The results of this test in Figure 6 in the form of a fixed band, is confirming the homogeneity of the data. The second condition is therefore also provides the use of regression.

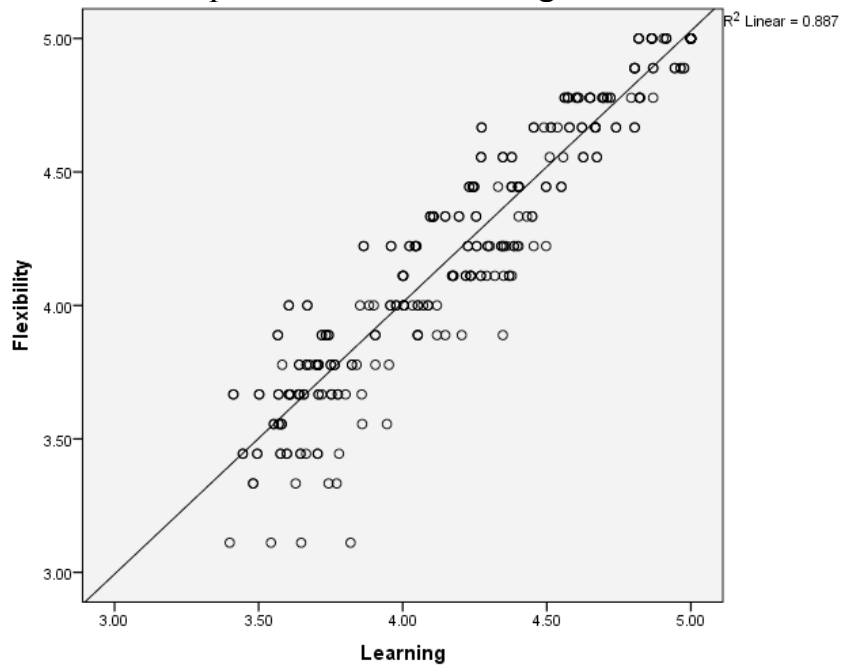

Figure 6 data scatter graph of organizational learning and flexibility

\section{Review the independence of errors}

One of the assumptions is included in the regression, independence of errors (difference between the actual values and values predicted by the regression equation) of each other.

If independence errors hypothesis is rejected and errors are not correlated with each other, there is not the possibility of regression. In order to evaluate the independence of the errors of each other the DurbinWatson test is used when results are shown in Table 7.

Table 7: Durbin-Watson test 


\begin{tabular}{|l|l|l|l|l|l|}
\hline Model & $\begin{array}{l}\text { correlati } \\
\text { on } \\
\text { coefficie } \\
\text { nt }\end{array}$ & $\begin{array}{l}\text { Determine } \\
\text { d coefficient } \\
\text { corrected } \\
\text { coefficient of } \\
\text { determination }\end{array}$ & Error value & $\begin{array}{l}\text { Durbin } \\
\text { Watson }\end{array}$ \\
\hline 1 & 0.942 & 0.887 & 0.877 & 0.165 & 2.02 \\
\hline
\end{tabular}

Given that the Durbin-Watson statistic in standard distance is 1.5 to 2.5. As a result of the absence of autocorrelation in the regression residuals or independence is confirmed. Therefore there is the third condition of regression.

\section{CONCLUSIONS}

Conclusion in this study, the relationship between organizational learning and flexibility of employees, the relationship between each dimension of organizational learning and flexibility among employees of education department of Sarpool-e-zahabcity tested and evaluated. The results showed a positive and significant relationship between organizational learning and flexibility of employee. According to the finding that there is a relationship between components of organizational culture and flexibility employees of education department of Sarpool-e-zahabcity with regard to the correlation coefficient (0.829) is accepted and approved by $95 \%$. That is to create an organizational culture increases the flexibility of the employees. According to the finding that there is a relationship between components of team work and learning and flexibility employees of education department of Sarpool-e-zahabcity with regard to the correlation coefficient (0.839) is accepted and approved by $95 \%$. This means that if the organization structure is so that provides context for problem-solving in groups can increase the flexibility of employees in the organization. Multiple regression tests showed that all aspects of organizational learning (shared vision, organizational culture, team work and learning, knowledge sharing, systems thinking, collaborative leadership and staff competence development) and flexibility affect employees. And according to the results of the regression betas to each variable, the most significant effect related to value of a shared vision in the organization $(\beta=0.428)$ has competence development of employees with beta coefficient $(\beta=0.056)$, with has less effect from the flexibility of employees accepted.

\section{REFERENCES}

1. Bodlaee, R. Koushki, and Sattari, R. (2011). Learning and organizational trust as an intermediary link between psychological empowerment and organizational commitment. Journal of management in the development process, Volume 24, Issue 1, Pages 67-93.

2. Arabi, Muhammad, Daneshparvar, M., (2007). Patterns flexibility in managing human resources, Journal of Management Studies, Issue 55.

3. Sobhaninejad Mahdi, Shahaee, B., Youzbashi, AR (2006). Learning Organization: Theoretical Foundations, implement and measure patterns. Tehran: Yastron 